\title{
Standardization in REACH in the context of active and healthy ageing
}

\author{
Christine Fuß Dipl.-Ing. ${ }^{\text {a,* }}$
}

Ann-Morla Meyer $\mathrm{MA}^{\mathrm{a}}$

\begin{abstract}
a'Department Innovation, DIN e. V. (German Institute for Standardization), Berlin, Germany; *Corresponding author: christine.fuss@din.de

C. Fuß, A.M. Meyer. Standardization in REACH in the context of active and healthy ageing. Gerontechnology 2017;16(3):196-199; https://doi.org/10.4017/gt.2017.16.3.009.00 Standardization is an important instrument to transfer research results and innovative knowledge into the market. It fosters dissemination and the availability of these results even after the end of the research project. Therefore, an overview of activities and planning in terms of standardization in the first year of REACH is provided. Standardization requires attention during the complete life span of a research project. Firstly, a research on existing standards and standardization activities related to the field of innovation has been conducted. Based on this a standardization strategy is envisaged that characterizes the next steps in project related standardization. The field of active and healthy ageing requires related standardization activities to enhance compatibility of innovative products and services. Standardization in REACH is an example for how to include standardization activities in a research project.
\end{abstract}

Keywords: standardization, standards, standards research, dissemination, ageing societies

Standardization in general describes an "activity of establishing, with regard to actual or potential problems, provisions for common and repeated use, aimed at the achievement of the optimum degree of order in a given context"1 ${ }^{\prime \prime}$. In context of research projects, the impact of strategical instruments of standards and standardization needs to be stressed out in order to use positive effects in the innovation process. The early communication between developers, operators and users is essential to define core requirements and needs, thus provide a basis for the sales market and enhances marketability of innovative solutions ${ }^{2}$. For instance, standardization of interfaces ensures compatibility of different components in one product. Standardization facilitates a less complex communication between different stakeholders. Therefore, transaction, information and adaptation costs can be reduced; economies of scale are generated when standards and standardization are considered within research and development projects ${ }^{3}$.

Standardization provides support of dissemination activities and transfers innovative knowledge into the market. That is why it is a major advantage for research and innovation projectsespecially in Europe with its Single Market and its resulting challenges. Early consideration of standardization aspects in research and innovation projects enhances the marketability of innovative products and services. Standards are relevant sources of knowledge, thus are relevant in most phases of the innovation cycle.

Active and healthy ageing is becoming a trend with wide-ranging implications in many societies. It fosters a development trend that will request standardization as well. Ageing societies, which demand active and healthy ageing, provide a lot of challenges but also opportunities for politics, industry, communities and science. The number of older consumers increases in most societies. The market of goods and services for older people provides new prospects in terms of commercial opportunities ${ }^{4}$. Innovations and new approaches are needed to meet the requirements of a changing customers group. But changes are not limited to the customer sideageing population also influences the change of workforce and work environments which can drive productivity ${ }^{5}$, it encourages public life and goes in full alignment with the approach of smart cities. The definition of 'older people' is changing. This aspect has to be considered in terms of all developments and trends in this area. People in the age of retirement want to live an independent, active and healthy live even being 65+.

The need for home care and healthcare services is strongly growing. Medical care and services are increasingly required. But other industries will be influenced, too. Fashions, entertainment, tourism, public transport, building industry are just a few 
areas to be named. These explanations underpin the broadness of the tendency for an active and healthy ageing not only on technological but also on economical, societal and political level ${ }^{5}$.

Standardization in context of ageing societies is an important area that needs to be thought of. Assistive systems as well as medical devices and many other technologies enable support of the daily life of older people by using sensors, e.g. for monitoring health conditions. These sensors will be connected to software and related platforms. Thus, a sufficient user interface will be needed and a lot of data will be generated, that needs to be dealt with in a secure and sufficient way. This is just one example which highlights the importance of standards in the field of active and healthy ageing. An increased longevity causes i.e. development of new products and services. Therefore, new standards and standardization activities will be required.

In terms of REACH the project consortium has been aware of the advantages of the early consideration of standardization. Already in the phase of proposal development and project planning standardization activities have been engaged. They will be used to transfer relevant research results into standardization. Even after the project terminates envisaged standardization documents will be publicly available to interested stakeholders.

The broad spread of topics in the field ageing societies can also be seen in the differentiation of the existing Technical Committees on European and international level. Some of them are listed in Tables 1 and 2.

The broadness of the field of research and many interleaving disciplines required an extensive research on existing standards and standardization activities that led to results that may have to be considered in further research activities within $\mathrm{REACH}$. To fulfil this requirement and in order to provide a comprehensive approach on stand-

Table 1. European Technical Committees relevant to REACH

European Technical Committees

CEN Healthcare Services Focus Group

CEN/TC 3

Quality management and corresponding general aspects for medical devices

\begin{tabular}{ll}
\hline CEN/TC 122 & Ergonomics \\
\hline CEN/TC 206 & Biological and clinical evaluation of medical devices \\
\hline CEN/TC 251 & Health informatics \\
\hline CEN/TC 293 & Assistive products for persons with disability \\
\hline CEN/TC 362 & Healthcare services-Quality management systems \\
\hline CEN/TC 431 & Service Chain for Social Care Alarms \\
\hline CEN/TC 449 & Quality of care for older people \\
\hline CEN/TC 450 & Patient involvement in person-centred care \\
\hline CEN-CENELEC Joint Working Group 5 & Design for All \\
\hline CEN/TC 224NWorking Group 6 & User interface
\end{tabular}
Title

ardization activities DIN, the German Institute for Standardization, has been responsible for a standardization research that was planned in the first year of the project.

The basis for the research on relevant standards in REACH was a set of keywords grouped in different clusters. Especially at the beginning of $\mathrm{REACH}$ and in order to meet the requirements of the project various possible solutions, products and applications need to be taken into account when preparing the standards research. To provide information for each of the possible research outcomes an extensive list of keywords has been gathered and clustered in cooperation with the project partners. This list of keywords contains terms as: monitoring devices, real time data exchange, health care services, usability (in context of Health care platforms) etc. Around 100 keywords were collected in collaboration with project partners. They have been structured in 6 clusters: equipment, services, health care platforms, testing and data collection, early/ preemptive intervention and an open category named 'others'. The compiled keywords have been used to perform the standards research within the DIN standards data base PERINORM. Beside the standards of European national organizations like e.g. DIN, NEN or BSI and NonEuropean national standardization organizations e.g. from Brazil, USA or South Africa, the database also includes standards from the European organizations CEN, CENELEC, ETSI and international organizations such as ISO, IEC and ITU ${ }^{6}$. More than thousand standards were identified in the context of the interdisciplinary research and development performed in the REACH research project. Technologies and services in the context of active and healthy ageing can be identified that are not yet developed or standardized by analyzing these keywords. This information provides a hint which areas are well suited for further research and development activities. During the PERINORM research, the list of entries presented per keyword was filtered. Entries were mostly filtered according to the categories home related services, selected IT applications and medicine. These product or service categories are close to the innovations that are expected to be developed within $\mathrm{REACH}$.

Afterwards the keywords have 
Table 2. International Technical Committees relevant to REACH

\begin{tabular}{ll}
\hline International Technical Committees & \\
\hline ISO/IEC Joint Technical Committee 1 & Information technology \\
\hline IOS/TC 83 & Sports and other recreational facilities and equipment \\
\hline ISO/TC 136 & Furniture \\
\hline ISO/TC 159 & Ergonomics \\
\hline ISO/TC 173 & Assistive products for persons with disability \\
\hline ISO/TC 194 & Biological and clinical evaluation of medical devices \\
\hline ISO/TC 210 & Quality management and corresponding general \\
\hline ISO/TC 215 & aspects for medical devices \\
\hline ISO/TC 304 & Health informatics \\
\hline ISO/COPOLCO & Healthcare administration \\
\hline IEC/TC 100 & Committee on consumer policy \\
\hline IEC System Committee AAL & Audio, video and multimedia systems and equipment- \\
\hline
\end{tabular}

Possible standardization activities on European level in context of a research project could be:

-Propose a specific topic (based on standardization needs identified in the project) to CCMC (CENCENELEC Management Center - CEN European Committee for Standardization, CENELEC European Committee for Electrotechnical Standardization) to establish a CEN workshop with the purpose of developing a CEN Workshop Agreement (CWA). This kind of standardization workshop is a flexible, open working platform for rapid development of standards at European level. CEN Workshop Agreements are voluntary in application and are obligatory reviewed every three years. Thus, it is a suitable solution for reaching consensus of identified stakeholders on technical specifications, guidance material, best practices etc. Those stakeholders are responsible for the content of the document ${ }^{7}$.

-Establish a liaison with appropriate Technical Committees. This liaison allows a research project representative to attend meetings of standardization committees as an observer. In that case REACH will demonstrate formal collaboration with the European Standardization System. Direct participation ensures synergies between research and standardization work as research results and ideas for future standardization activities can be communicated. Duplication of standardization work can be avoided. New work items can be proposed by the project representative to the specific Technical Committee. A new work item represents the first step towards a fullconsensus European standard (EN) that will be developed within the Technical Committee ${ }^{8}$.

As active and healthy ageing is a worldwide topic, the international standardization level should also be considered. First steps have been taken to align with the international standardization world by joining the ISO (ISO International Organization for Standardization'. Strategic Advisory Group (SAG) on Ageing Societies. A representative of $\mathrm{REACH}$ has been announced as German expert to attend the ISO SAG. Purpose of this group is to provide advice to the Technical Management Board of ISO, which carries out the overall management of the technical work of ISO. Work has been focused on identification of challenges and opportunities as well as on a 
gap analysis of existing national, regional and international standards to identify already available knowledge. These results have been used to identify priority areas for ISO standardization and to provide recommendations for the ISO Technical Management Board. Future developments on ISO level will be monitored and taken into consideration when deciding on project related standardization aspects. In terms of Ageing Societies, it can be mentioned that a number of standardization activities are expected. Areas such as terminology, ageing workforce, universal design, accessibility and new technologies and systems might be in the focus of future standardization activities. In the field of health promotion and preventative care in older age will derive standardization requirements and needs, which will be of importance for REACH.

Summarizing current developments and research approaches of $\mathrm{REACH}$ from the standardization point of view the field of health promotion and preventative care in older age is a focus topic. This status is underlined by the outcomes of the ISO SAG on Ageing Societies. The project aims to facilitate the transfer of research results into standardization to foster a broad dissemination. The development of solutions that stand alone without being related to existing conditions won't be successful in the market. Standardization is a powerful tool to ensure matching of interfaces and interoperability with other solutions available on the market. It enhances a simple implementation and application, especially as interdisciplinary collaboration between different stakeholders is essential. REACH aims to benefit from these standardization advantages by creating a standardization strategy that handles challenges due to the broadness of the topic active and healthy ageing and focusing on encouraging standardization activities.

\section{Acknowledgements}

The REACH project has received funding from European Union's Horizon 2020 research and innovation programme under grant agreement No 690425.

\section{References}

1. CEN, EN 45020 Standardization and related activities - General vocabulary (ISO/IEC Guide 2:2004); https://www.beuth.de/de/norm/dinen-45020/95609390

2. Konrad A, Zlocysti P. Standardization and innovation are no opposites. Wochenbericht des DIW Berlin 40, Berlin, 2010, p.10-15; http://www.diw. de/sixcms/detail.php?id=diw_01.c.454906.de, retrieved May 24, 2017

3. Fuß C, Behrens H, R\&D Phase Standardization of use cases for mobile assistance systems in the field of technical services. In: Nüttgens $\mathrm{M}$, Thomas $\mathrm{O}$, Fellmann M, editors. Dienstleistungsproduktivität, Wiesbaden, Springer Gabler 2014, pp155-164; https://doi.org/10.1007/978-3-658-05301-7_10

4. Elizabeth Gaslorowski-Denis. The silver economy, ISO: ISOfocus March-April 2017 Active Ageing

2017; pp 8f; https://www.iso.org/files/live/sites/ isoorg/files/news/magazine/ISOfocus\%20(2013NOW)/en/2017/ISOfocus_121/ISOfocus_121_ EN.pdf; retrieved May 24, 2017

5. World Economic Forum: How 21st -century longevity can create markets and drive economic growth 2015; pp 5; http://www3.weforum.org/ docs/WEF_GAC_Ageing_White_Paper.pdf; retrieved May 24, 2017

6. Linner T, Steinhardt E, Güttler J (TUM); Fuß C, Meyer AM (DIN); Andersen HB (DTU). REACH D6.1 Applicable standards and best practice guidelines for all REACH related activities 2017, pp 37f; http://reach2020.eu/?page_id=1190; retrieved October 19, 2017

7. CEN CENELEC 2017; http://www.cen.eu/work/ products/CWA/Pages/default.aspx; retrieved October 19, 2017

8. CEN CENELEC 2017; https://www.cencenelec.eu/ research/tools/projects/ongoingENwork/Pages/default.aspx; retrieved October 10, 2017 